\title{
Cold-Start and Warm-Up Driveability Performance of Hybrid Electric Vehicles Using Oxygenated Fuels
}

\author{
Matthew Thornton \\ National Renewable Energy Laboratory \\ Scott Jorgensen \\ General Motors \\ Beth Evans \\ Evans Research Consultants \\ Ken Wright \\ ConocoPhillips
}

\begin{abstract}
Hybrid vehicles may respond to fuel variables in unique ways; they could even require a unique driveability test. The Coordinating Research Council (CRC) conducted a program to determine the effect of ethanol content on driveability performance under cool ambient conditions. In addition to the 27 vehicles in the main fleet, four hybrid electric vehicles (HEVs) were tested using the same fuels and driveability procedure. These HEVs responded to fuel in a manner similar to conventional vehicles; however, the HEVs showed unique driving characteristics not well captured in the existing test.
\end{abstract}

\section{INTRODUCTION}

The Coordinating Research Council (CRC) Volatility Group conducted a program in January and February of 2003 to determine the effect of ethanol content on coldstart and warm-up driveability performance under cool ambient conditions in a large group of late-model vehicles equipped with fuel-injection systems. The goal of the program was to develop concentration-dependent cold-start and warm-up driveability equations for the oxygenate offset of ethanol at cool ambient temperature. The Volatility Group tested 27 vehicles, which were selected from a total fleet of 80 vehicles, based on their response to driveability index (DI) using the highest DI fuel with the highest concentration of ethanol-10 percent.

In addition to these 27 vehicles, the CRC Advanced Vehicle Fuel and Lubricant (AVFL) Committee requested that the Volatility Group test a small number of hybrid electric vehicles (HEVs) using the same fuels and driveability procedure as the core program. The four hybrid vehicles tested included a Honda Civic, a Toyota Prius, and two Honda Insights.

This paper details the analysis and results of the driveability performance testing from the four HEVs. The paper also includes a discussion of the four vehicles, the fuels used, the test location, procedures, and conditions. The results from the 27 conventional vehicles used in the core program will be published in a separate CRC report.

The results of the test on the HEVs showed that, as with conventional vehicles, there is a statistically significant effect of fuel ethanol content on the driveability of HEVs. In addition, the three HEV models that were tested each acted differently and had individual idiosyncrasies that need to be taken into account. Whereas conventional vehicles can all be rated in the same manner, hybrid vehicles do not act similarly enough to be able to rate them using the conventional vehicle test method. This finding led to the conclusion that driveabilty test procedures unique to the evaluation of HEVs should be developed to better understand the performance of HEVs. The following will discuss these results and the recommendation for a specialized driveability test for HEVs.

\section{HYBRID ELECTRIC VEHICLES TESTED}

For this piggyback project four HEVs were used. These vehicles included one Honda Civic, two Honda Insights, and one Toyota Prius. The 2003 Civic rented for use in the project provided the newest production hybrid electric technology of the four vehicles. The mileage on the Civic at the end of the testing was 13,000. One 2000 Insight was provided by ConocoPhillips and had the highest mileage accumulation of all of the HEVs tested $(16,600$ 
mi). The National Renewable Energy Laboratory (NREL) loaned an additional 2000 Insight and a 2001 Prius to the project. These two vehicles had the lowest mileage levels of all four of the HEVs, 3200 and 6600 miles respectively.

The Honda Insight and Toyota Prius were the first two HEVs commercially available in the United States. These two vehicles have some very basic similarities - both combine power from a gasoline engine with an electric motor and a nickel-metal hydride (NiMH) battery pack to provide motive force. The Honda Insight has a smaller pack that consists of 20 modules, each having six Dsized spiral-wound cells (see Figure 1). The total pack nominal voltage is 144 volts $(\mathrm{V})$. The total energy capacity of the Insight pack is $936 \mathrm{Wh}$. The ends of the $20 \mathrm{D}$-sized modules can be seen in Figure 1. Also shown are the fan and the outside of the ducting that directs cabin air across the modules for cooling. The larger Prius battery pack is a later generation $\mathrm{NiMH}$ design that consists of 38 prismatic modules, each having six, $1.2 \mathrm{~V}$ cells. The total pack nominal voltage is $273.6 \mathrm{~V}$. The total energy capacity is 1778.4 watt hours (Wh). Figure 2 shows the Prius pack with the 38 prismatic modules as they are arranged in the pack (3).

The Honda Insight is a light-weight (856 kilogram (kg) curb weight), two-passenger hatchback powered by a 50 kilowatt (kW) gasoline engine with additional assist power provided by a $10 \mathrm{~kW}$ electric motor. The Insight has a parallel HEV configuration and has manual transmission. The electric motor is coupled directly to the drive shaft of the engine and provides additional power for relatively hard accelerations. It also operates as a generator to recapture kinetic energy during deceleration and helps balance vibrations of the in-line three-cylinder, 1.0-liter engine $(4,5)$.

The Toyota Prius is a five-passenger compact sedan powered by a $52 \mathrm{~kW}$ gasoline engine and a $33 \mathrm{~kW}$ electric motor. It has a curb weight of $1254 \mathrm{~kg}$. The Prius has a more complex dual-mode hybrid configuration where energy to and from the vehicle wheels can travel along several different pathways. Mechanical energy to the wheels passes through a planetary gear set that couples the engine, electric motor, and generator to the final drive. Power to the wheels can be provided solely by the battery pack through the electric motor, directly from the gasoline engine to the wheels, or from a combination of both the motor and the engine. The battery pack can be recharged directly by energy taken from the wheels through the generator (regenerative braking) or from excess energy from the gasoline engine (also turning the generator) (3). The Prius utilizes an electronically controlled continuously variable transmission (ECVT).

The Honda Civic is the most recent HEV to be released for public sales. The Civic is powered by a gasoline engine with an electric motor and a NiMH battery pack, similar to the Insight, although the four-cylinder, 1.5-liter engine is 50 percent larger. The Civic is a five-passenger compact sedan powered by a $63 \mathrm{~kW}$ gasoline engine and a $10 \mathrm{~kW}$ electric motor. The Civic is also configured with the continuously variable transmission (CVT). It has a curb weight of $1239 \mathrm{~kg}$. The Civic has a battery pack that consists of 120 cells at $1.2 \mathrm{~V}$ each. The total pack nominal voltage is $144 \mathrm{~V}(6)$.

Previous testing on the Insight and Prius at NREL provided some information related to the unique performance of these vehicles and their battery packs. NREL's testing of the Honda Insight and Toyota Prius has revealed or quantified the results of a number of design differences that affect battery usage. These differences are due in part to the geometry and design of the packs, but also in large part to the design of the vehicle and control systems. Both vehicles have 6.5 ampere hours (Ah) NiMH battery packs, but the Prius pack is a later-generation prismatic design that is also significantly larger, corresponding to the more intensive use of the car's electric motor. The Prius' $33 \mathrm{~kW}$ electric motor is used in a wider range of applications including all-electric propulsion under low-load, low-speed conditions.

Testing showed that the Insight limited pack usage to approximately $60 \%$ of the rated 6.5 Ah capacity, while the Prius was limited to $40 \%$. The Prius control strategy features a target indicated battery pack state of charge (SOC) of approximately $56 \%$. Use of the battery and electric motor are strongly influenced by this target. The Insight apparently has a much broader range in which the SOC is controlled and no single target SOC. The Prius uses substantially more battery energy over a given driving cycle. For the Prius, the amount of propulsion energy supplied by the battery was nearly $10 \%$ of the gasoline fuel energy used by the engine on the Federal Test Procedure (FTP) driving cycle. The highest level of pack energy used by the Insight was $3 \%$ of the fuel energy for the SC03 cycle with air conditioning (3). The implications of these differences on the results of this program and impacts on future programs will be discussed in detail in a later section.

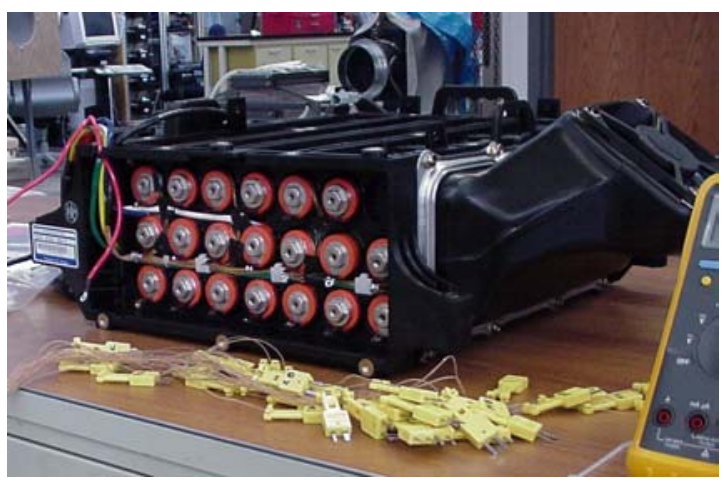

Figure 1, Honda Insight Battery Pack 


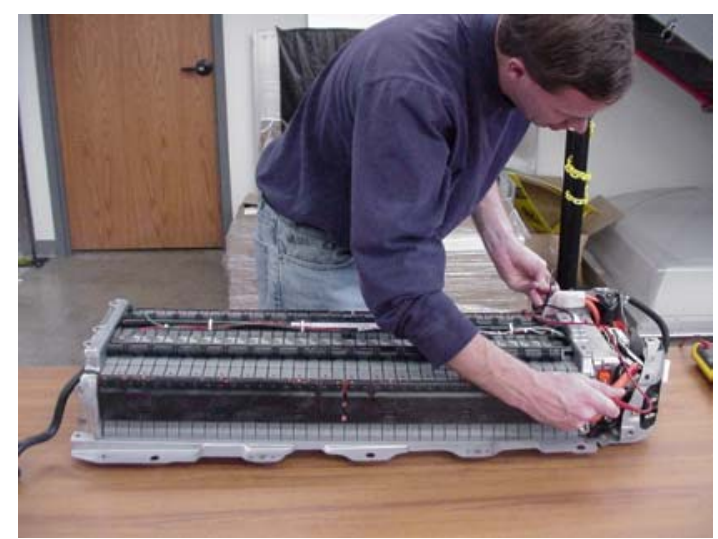

Figure 2, Toyota Prius Battery Pack

\section{TEST FUELS}

The fuel matrix used for this program consisted of ten fuels; a high driveability index (DI) (1300) hydrocarbon base fuel with a nominal 7-psi vapor pressure and nine different blended test fuels. Three test fuels were prepared by splash blending 3,6 , and 10 volume percent ethanol into the base fuel (E1, E2, and E3). Three hydrocarbon-only test fuels were prepared by adding a light hydrocarbon mixture to the base fuel to roughly match the Dls $(10 \%, 50 \%$, and $90 \%$ evaporated points) of the three splash ethanol blends $(\mathrm{H} 1, \mathrm{H} 2$, and $\mathrm{H} 3)$. The final three fuels were prepared by mixing 3,6 , and 10 volume percent ethanol with hydrocarbon gasoline components to meet a constant 1300 maximum DI limit for all three fuels (E4, E5, and E6). Samples were obtained on-site and shipped to a volunteer's laboratory facility for inspection. These specifications are shown below in Table 1. Indeed, all of the fuel used in this study exhibited a very high DI, all exceeding the maximum ASTM DI specification of 1250 . The occurrence of fuels of this nature in the field, are currently rare, but they are occasionally experienced.

Table 1. Test Fuel Specifications

\begin{tabular}{|c|c|c|c|c|c|c|c|c|c|c|c|}
\hline Inspection & Units & Base & E1 & E2 & E3 & H1 & $\mathrm{H} 2$ & H3 & E4 & E5 & E6 \\
\hline API Gravity & ${ }^{\circ} \mathrm{API}$ & 53.8 & 53.7 & 53.7 & 53.4 & 55.2 & 55.3 & 55.8 & 51.8 & 51.6 & 50.7 \\
\hline Relative Density & $60 / 60^{\circ} \mathrm{F}$ & 0.7638 & 0.7638 & 0.7642 & 0.7654 & 0.7578 & 0.7577 & 0.7555 & 0.7721 & 0.7729 & 0.7766 \\
\hline DVPE & psi & 7.81 & 8.91 & 9.02 & 8.90 & 8.77 & 8.81 & 8.90 & 7.91 & 8.00 & 8.00 \\
\hline \multicolumn{12}{|l|}{ Oxygenates--D 4815} \\
\hline MTBE & vol\% & 0.0 & 0.0 & 0.0 & 0.0 & 0.0 & 0.0 & 0.0 & 0.0 & 0.0 & 0.0 \\
\hline TAME & vol\% & 0.0 & 0.0 & 0.0 & 0.0 & 0.0 & 0.0 & 0.0 & 0.0 & 0.0 & 0.0 \\
\hline EtOH & vol\% & 0.0 & 3.2 & 6.1 & 10.6 & 0.0 & 0.0 & 0.0 & 3.3 & 6.0 & 10.2 \\
\hline O2 & wt \% & 0.0 & 1.15 & 2.19 & 3.83 & 0.0 & 0.0 & 0.0 & 1.19 & 2.13 & 3.64 \\
\hline \multicolumn{12}{|l|}{ D 86 Distillation } \\
\hline IBP & ${ }^{\circ} \mathrm{F}$ & 90.6 & 94.4 & 94.1 & 96.4 & 87.2 & 89.0 & 87.6 & 94.2 & 99.4 & 102.0 \\
\hline $5 \%$ Evaporated & ${ }^{\circ} \mathrm{F}$ & 121.0 & 116.8 & 118.0 & 120.5 & 114.0 & 115.5 & 114.8 & 122.8 & 124.5 & 127.7 \\
\hline $10 \%$ Evaporated & ${ }^{\circ} \mathrm{F}$ & 139.1 & 126.0 & 128.3 & 130.1 & 128.5 & 131.4 & 130.1 & 132.1 & 134.1 & 137.8 \\
\hline $20 \%$ Evaporated & ${ }^{\circ} \mathrm{F}$ & 171.9 & 147.1 & 143.0 & 144.9 & 157.3 & 160.6 & 159.2 & 155.6 & 146.9 & 151.4 \\
\hline $30 \%$ Evaporated & ${ }^{\circ} \mathrm{F}$ & 206.3 & 192.4 & 161.3 & 155.7 & 192.3 & 193.0 & 189.6 & 202.9 & 176.3 & 159.7 \\
\hline $40 \%$ Evaporated & ${ }^{\circ} \mathrm{F}$ & 231.7 & 226.8 & 219.8 & 171.7 & 224.5 & 223.4 & 216.6 & 232.6 & 226.1 & 212.1 \\
\hline $50 \%$ Evaporated & ${ }^{\circ} \mathrm{F}$ & 248.0 & 244.8 & 242.8 & 236.6 & 244.4 & 244.5 & 238.0 & 250.3 & 246.3 & 249.4 \\
\hline $60 \%$ Evaporated & ${ }^{\circ} \mathrm{F}$ & 265.6 & 262.5 & 260.3 & 256.0 & 264.1 & 265.7 & 261.2 & 271.5 & 269.9 & 268.5 \\
\hline $70 \%$ Evaporated & ${ }^{\circ} \mathrm{F}$ & 297.2 & 292.3 & 288.8 & 283.1 & 296.1 & 297.3 & 297.1 & 280.3 & 304.4 & 303.8 \\
\hline $80 \%$ Evaporated & ${ }^{\circ} \mathrm{F}$ & 327.2 & 325.4 & 324.5 & 322.1 & 325.7 & 326.1 & 325.0 & 332.0 & 331.4 & 331.8 \\
\hline 90\% Evaporated & ${ }^{\circ} \mathrm{F}$ & 343.4 & 342.9 & 342.3 & 341.6 & 341.0 & 340.3 & 337.9 & 346.4 & 347.2 & 346.6 \\
\hline 95\% Evaporated & ${ }^{\circ} \mathrm{F}$ & 357.2 & 356.4 & 356.2 & 355.5 & 353.9 & 351.9 & 348.6 & 361.0 & 361.5 & 360.4 \\
\hline EP & ${ }^{\circ} \mathrm{F}$ & 386.3 & 380.7 & 384.9 & 382.4 & 383.0 & 379.9 & 376.6 & 390.8 & 390.9 & 386.2 \\
\hline Recovery & vol\% & 97.9 & 97.7 & 97.5 & 97.8 & 98.0 & 97.5 & 97.6 & 98.1 & 98.0 & 97.9 \\
\hline Residue & vol\% & 0.9 & 1.0 & 1.1 & 1.0 & 0.9 & 1.1 & 0.9 & 0.9 & 0.8 & 1.0 \\
\hline Loss & vol\% & 1.2 & 1.3 & 1.4 & 1.2 & 1.1 & 1.4 & 1.5 & 1.0 & 1.2 & 1.0 \\
\hline $\begin{array}{r}\text { Percent Evaporated } \\
\text { at } 158^{\circ} \mathrm{F}\end{array}$ & vol\% & 15.9 & 22.7 & 29.2 & 32.2 & 20.0 & 19.2 & 19.8 & 20.7 & 24.6 & 29.4 \\
\hline $\begin{array}{r}\text { Percent Evaporated } \\
\text { at } 200^{\circ} \mathrm{F}\end{array}$ & vol\% & 28.0 & 32.1 & 36.6 & 44.4 & 32.3 & 32.1 & 33.8 & 29.4 & 34.7 & 37.7 \\
\hline $\begin{array}{r}\text { Percent Evaporated } \\
\text { at } 250^{\circ} \mathrm{F}\end{array}$ & vol\% & 51.3 & 53.4 & 54.6 & 56.4 & 53.5 & 53.0 & 55.5 & 50.0 & 52.0 & 50.2 \\
\hline $\begin{array}{r}\text { Percent Evaporated } \\
\text { at } 300^{\circ} \mathrm{F}\end{array}$ & vol\% & 71.1 & 72.2 & 73.3 & 74.3 & 71.6 & 71.0 & 71.0 & 74.1 & 68.7 & 69.1 \\
\hline Driveability Index & & 1295.9 & 1266.4 & 1263.3 & 1246.6 & 1267.1 & 1270.9 & 1247.0 & 1295.4 & 1287.2 & 1301.4 \\
\hline
\end{tabular}




\section{TEST LOCATION}

The test program was conducted at the Renegade Raceways near Yakima, Washington, in the valley of the Yakima River. The raceways are at an altitude of 990 feet. The test site was a 0.7 -mile long, 60 -foot wide, flat, paved, two-lane drag strip, along with several adjacent single-lane, paved, auxiliary roads normally used for racecar preparation. A large, rectangular, paved area suitable for defueling/refueling and vehicle storage also was utilized. The race staging area at the base of the track was used for soaking the vehicles overnight.

\section{TEST PROCEDURE}

The test fuels were evaluated as prescribed in the CRC Cold-Start and Warm-up Driveability Procedure (E-2894) (2). Duplicate tests were performed on every vehicle and fuel combination.

The CRC Cold-Start and Warm-up Driveability Procedure consists of a series of light, moderate, and wide-open-throttle maneuvers mixed in with idles to obtain as many evaluations of driveability in a cold engine as possible (2). Figure 3 shows one of the Insights during an acceleration maneuver at the Renegade Raceway. Malfunctions are evaluated and recorded as being trace, moderate, heavy, or extreme. The absence of malfunctions was recorded as clear or clean. During set-up week, the raters were provided with all the test vehicles to set individual vehicle vacuum targets and more importantly to allow them to agree on a similar definition of malfunction severity.

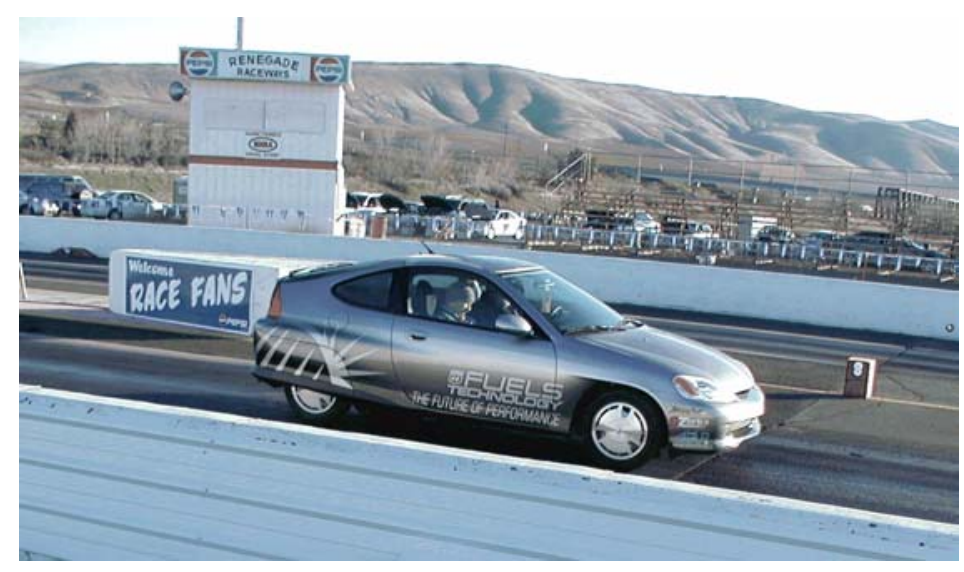

Figure 3. Insight During Acceleration Maneuver

All vehicles were tested each day using three raters and three data loggers, with a specific rater assigned to exclusively test the same vehicles for the entire program. Three raters were used throughout the program. Each vehicle was assigned its own fuel each day.

The three rating teams tested the fleet of 31 vehicles in three hours. Generally, three vehicles were on the track simultaneously, separated by approximately 0.3 miles. Overtaking a severely malfunctioning or stalled vehicle was accomplished in a safe predetermined manner. No problems with vehicles impeding one another were encountered using this schedule, even though stalls and severe malfunctions did occur.

\section{TEST CONDITIONS}

Temperatures at this location were stable for around three to four hours bracketing dawn. The overnight soak temperatures ranged from $22^{\circ} \mathrm{F}$ to $37^{\circ} \mathrm{F}$ (with the exception of one night at $15^{\circ} \mathrm{F}$ ). The mean soak temperature was $31.9^{\circ} \mathrm{F}$. All tests were carried out in the test-temperature range of $30^{\circ} \mathrm{F}$ to $42^{\circ} \mathrm{F}$ and 97.3 percent of the tests for all the 31 vehicles fell inside the planned temperature window of $30^{\circ} \mathrm{F}$ to $40^{\circ} \mathrm{F}$. The mean test-temperature was $37.0^{\circ} \mathrm{F}$.

\section{RESULTS}

The results presented in this paper are divided into two sections: One section focuses on the analytical results while the second section discusses the subjective information gained from the program. Since all of the information reported in this section is limited to a small amount of data collected from only four HEVs, these results should not necessarily be applied to all HEVs.

\section{ANALYTICAL ANALYSIS}

Two data points were obtained for all four HEVs on each of the 10 fuels for a total of 80 tests. The diligent efforts of the field team produced data in a well controlled temperature range, despite the fact the hybrids were the last vehicles tested each day. If there was any danger of exceeding the specified temperature range for the primary test fleet the tests were postponed to the following day. All tests were conducted in a runtemperature window of $30^{\circ} \mathrm{F}$ to $42^{\circ} \mathrm{F}$ inclusive.

Rater and vehicle are confounded in this analysis because each vehicle was assigned to a rater. Thus, any statements about rater or vehicle alone are unsupported; the variable car will present the combined effect. Car was treated as a class variable in all the analyses, while all the other variables were centered and treated numerically in the analysis. The SAS system for windows release 8.02 was used for the analysis (7).

First the normality of the data was appraised using the SAS procedure proc Univariate. The data were reasonably normal (minimum 8 , mean 60 , maximum 164, and standard deviation 36.8) but skewed (skewness $=0.84$ ), and the variance increased with magnitude. In order to more closely approximate the assumptions of normal statistics the transform $Y=L n($ Total Weighted Demerits $(T W D)+1$ ) was used. This improved the normality of the dependent variable. The mean of the transform was 3.91 relative to a minimum and maximum of 2.2 and 5.1 , with a standard deviation of 0.68 , and a skewness of -0.44 (see Appendix A). 
Having established a normal dataset, the analysis was conducted on centered variables using proc GLM. All nonsignificant variables were dropped. The effects that remained were car, soak, ethanol, and DI, plus an intercept. Car, DI and the intercept were significant at alpha $=0.0001$ (99.99\% confidence), while ethanol and soak temperature were significant at alpha $=0.014$ and 0.044 respectively. The coefficients are provided in Table 2, below.

\section{Table 2. Regression Statistics}

\begin{tabular}{|l|l|l|l|l|}
\hline \multicolumn{7}{|c|}{ Standard } \\
\hline Parameter & Estimate & Error & $\mathrm{t}$ Value & $\mathrm{Pr}>|\mathrm{t}|$ \\
\hline intercept & $-0.857108113 \mathrm{~B}$ & 0.08646489 & -9.91 & $<.0001$ \\
\hline Car 84 & $1.150603940 \mathrm{~B}$ & 0.12228066 & 9.41 & $<.0001$ \\
\hline Car 85 & $1.116298275 \mathrm{~B}$ & 0.12227970 & 9.13 & $<.0001$ \\
\hline Car 86 & $1.161530238 \mathrm{~B}$ & 0.12227970 & 9.50 & $<.0001$ \\
\hline Car 87 & $0.000000000 \mathrm{~B}$ & & & \\
\hline DI & 0.010832567 & 0.00229222 & 4.73 & $<.0001$ \\
\hline ethanol & 0.028083738 & 0.01110476 & 2.53 & 0.0136 \\
\hline soak & -0.019839109 & 0.00968464 & -2.05 & 0.0441 \\
\hline
\end{tabular}

Car is a class variable that represents the contribution of the car/driver combination, $\mathrm{DI}$ is a continuous variable representing the driveability index in degrees $F$, ethanol is a continuous variable representing the percent ethanol, and soak is a continuous variable representing the overnight minimum temperature in degrees $F$. The "B" following some of the estimates indicates that the result is referenced to a specific class level being set arbitrarily to zero. In this case all the other car/rater combinations are referenced to car/rater 87 . The intercept is also referenced to this value. This process is common when class variables are used. It cannot be over emphasized that the results and significance levels apply to this fleet in this test, not to all HEVs.

The overall regression has an $\mathrm{F}$ value of 28.05 and a probability of higher $F$ of $<0.0001$. Car rater combinations 84,85 , and 86 were all significantly different from car/rater combination 87 (see Table 2), but were not significantly different from each other $(90 \%$ confidence level).

Least squares (LS) means (a best estimate of the mean taking all other factors into account) were calculated for each vehicle and in a separate regression with fuel as a class variable for each fuel. The results are presented graphically below in Figures 4 and 5 . The six splash blended fuels were not significant from each other $(90 \%$ confidence level) overall regression $\mathrm{F}=15.3$, $\mathrm{Pr}>\mathrm{F}$ $<.0001$. The lower match blends were not different from the base fuel, but the highest blend (fuel E6 in Figure 4) was different $(90 \%$ confidence level) overall regression $\mathrm{F}=15.3$, $\mathrm{Pr}>\mathrm{F}<.0001$. The two higher ethanol content match blends were significantly different from all splash blends (98 to $99.99 \%$ confidence level) but the lowest match blend was generally not different from the spalsh blends (90\% confidence level overall regression $\mathrm{F}=15.3$, $\mathrm{Pr}>\mathrm{F}<.0001)$. The two Insights and Prius were not significantly different $(90 \%$ confidence level), but were different from the Civic (99.99 confidence level overall regression $\mathrm{F}=28.05, \mathrm{Pr}>\mathrm{F}<.0001$ ) see Figure 5.

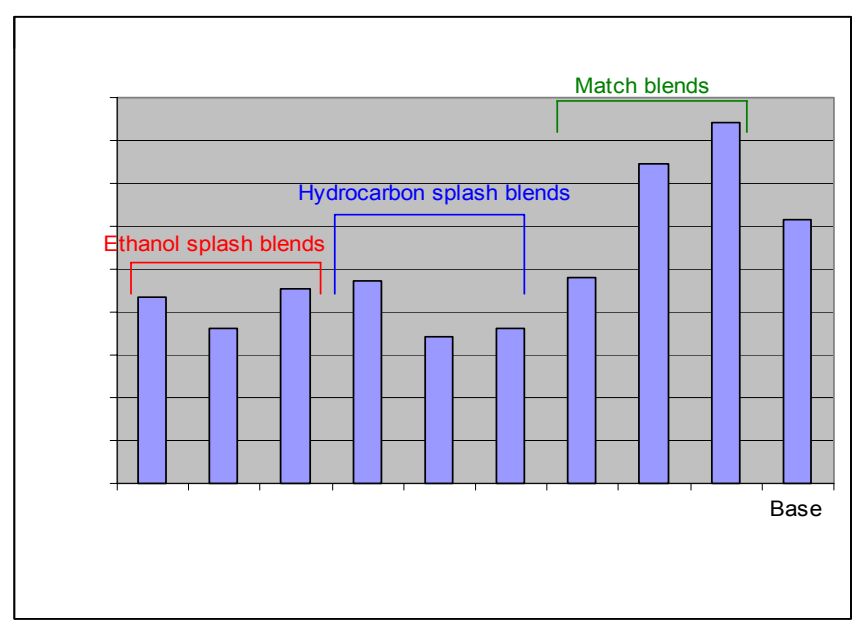

Figure 4. HEV Driveability Fuel Dependent Results

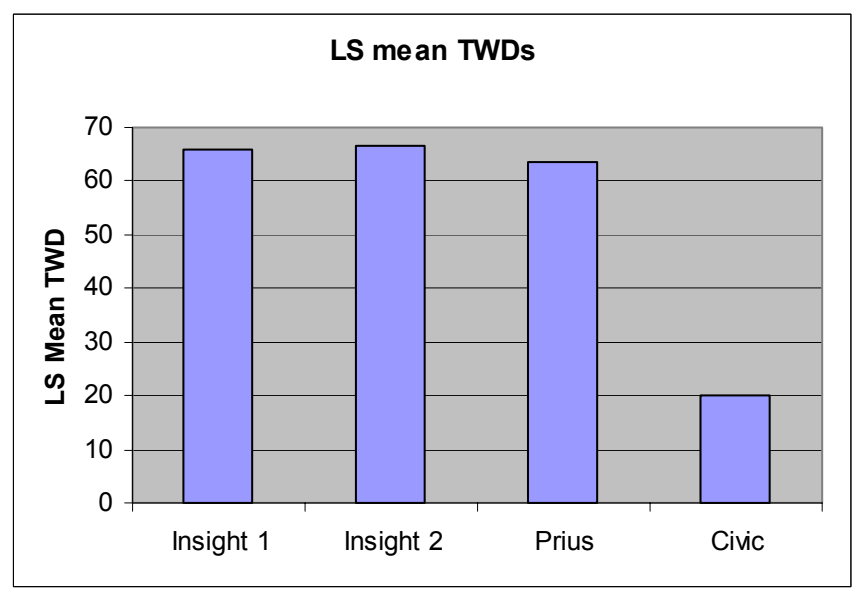

Figure 5. HEV Driveability Test Demerit Results

\section{SUBJECTIVE ANALYSIS}

The three hybrid models each act differently and have individual idiosyncrasies, which must be taken into account. Whereas conventional vehicles can all be rated in the same manner, hybrid vehicles do not act similarly enough to be able to rate them all in the same manner with the current test.

The first obvious challenge is that the CRC Driveability Procedure was developed for automatic transmissions; however, the two Insights were equipped with manual transmissions. One rater was assigned both Insights in this program in an attempt to omit the shifting variability inherent among drivers. The rater determined the shift points for each maneuver before the test program began. The rater determining the shift points attempted to simulate the shift points of an automatic transmission so that the transition between gears was as natural as possible. Different shift points may be necessary for different models. Also, there is only one idle rating applicable during the starting procedure; there is no "Drive" idle rating. The detent maneuver is not applicable 
for manual transmissions either; detent was performed at wide-open-throttle in second gear.

The Insights also have an idiosyncrasy in their start times. Several times, they would quit cranking before the normal five seconds allowed. The rater would still have the key in the crank position, but they would stop cranking on their own. The rater would then release the key, turn the key off and on again to re-pressurize the fuel rail, and begin cranking again, and the same thing might or might not happen. These were recorded in the database as no-starts, although a conventional no-start situation occurs when the vehicle continues cranking for five seconds and does not start.

All four of the HEVs tested in this program used the electric motor to start the engine rather than conventional starters. It was observed that while on tank fuel, the Prius would start so imperceptibly that it was impossible to tell when it actually started. The rater was concerned how to record start times during testing. When the same vehicle was started on test fuel, the cranking time became obvious and the rater could tell exactly when the vehicle started. This could be an issue if testing a fuel that gives good starting performance.

One of the idiosyncrasies of the Prius is that it would completely stall and then re-start the engine on its own, with no action on the rater's part. This occurred several times with the Prius and once with one of the Insights. This behavior is not well captured with the current test.

Hybrids can be designed to operate differently, such as the Honda and Toyota vehicles tested. The Honda HEVs provide electric motor assist to a small gasoline engine during take-off and acceleration. When slowing down or braking, energy is recaptured by the same motor serving as a generator. Like the Prius, the Honda system incorporates an idle-stop feature that shuts off the engine at traffic lights. The Toyota Prius operation is based on the driving mode the vehicle is under. The Prius operation can be by the gasoline engine, the electric motor, or a combination of both.

Conventional ratings do not always apply to the hybrids. One example is with the Prius. The rater testing the Prius had to develop a unique rating scheme for hesitation with that car. The car would move forward when the accelerator was depressed, but fuel quality had a definite impact on the car's movement. The car might move forward with the vacuum staying at the idle vacuum (nominally 15 inches). Sometimes the car might move forward with a delay in the vacuum dropping to the three inches of light-throttle vacuum. Other times the car might move forward with an immediate vacuum response. Sometimes, the rater could feel the engine engage or "kick in" and sometimes the rater could tell the engine had not "kicked in" during the maneuver.

The preconditioning cycle is another area in which the hybrids are very individualistic. Each model required a different preconditioning cycle to adequately recharge the assist battery. Depending upon the way the Insights were driven, they could use the same preconditioning cycle the conventional vehicles used; however, if they were not driven optimally, this cycle could deplete the assist battery to less than a quarter charge. The Civic required excessively mild accelerations or the battery would be completely depleted, and it could not use the conventional preconditioning cycle. The Prius could be preconditioned using the conventional cycle, but it required moderately mild accelerations. It quickly became obvious that the preconditioning drivers needed to be "trained" how to drive the vehicles to successfully charge them.

The battery charge seems to affect when the battery assist engages. The battery-assist appears to affect engine vacuum. There is some question whether the battery-assist on the hybrids can either simulate or cover-up malfunctions when it engages. The raters made every effort to rate fuel-related malfunctions rather than battery-oriented behavior. Increasing familiarity with the operation of the various hybrids made it easier to distinguish between fuel-related malfunctions and battery-oriented behavior. The raters agreed that becoming familiar with the vehicles is a necessity; in fact, in most cases, it took about a week of testing before the raters began to feel comfortable with the hybrid assigned to them.

All the hybrid vehicles were de-fueled, flushed, and refueled using a modified version of the standard CRC fueling procedure. The standard fueling procedure had been developed by the CRC Volatility Group from a study to reduce fuel carryover from one test to the next when flushing vehicle fuel tanks $(2,8,9)$. Figure 6 below shows the two Insights during de-fueled, flushed, and refueled.

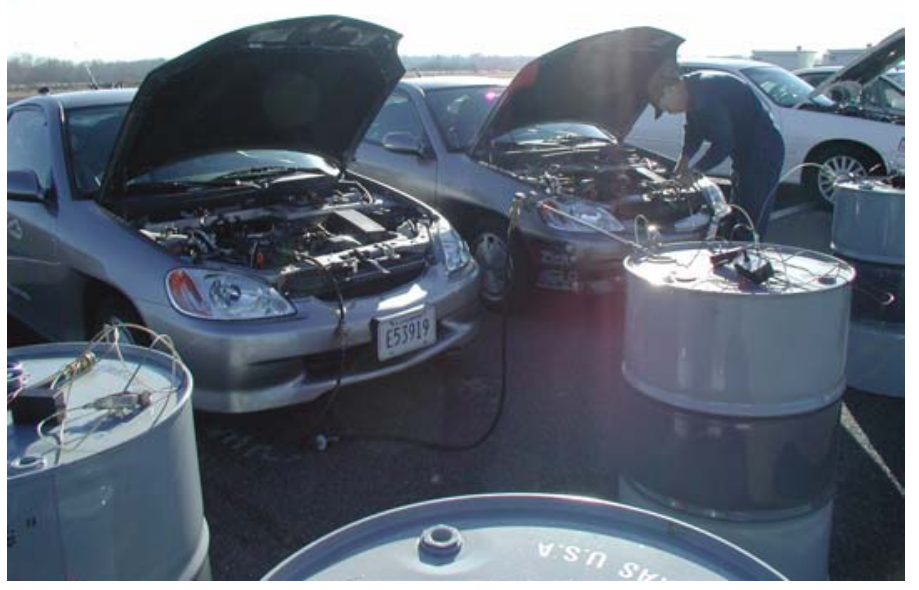

Figure 6. Two Honda Insights Being De-fueled, Flushed, and Refueled

Changes to the refueling procedure were to address concerns on battery state of charge and time to refuel. In order to maintain constant battery charge levels, the 
engines were operated during de-fueling. To reduce overall refueling time, the amount of gasoline used to flush and refuel was changed from four gallons to two gallons. Since these hybrid vehicles had smaller fuel tanks than conventional vehicles, smaller fill size is allowed in the CRC fueling procedure. But even at a 50\% reduction in fuel to be drained, the Civic and Prius took longer to de-fuel than most other test vehicles. The drain valve on the Insights needed to be adjusted every five minutes or so, or else surging from the fuel pump would stall the engine. With close attention, the Insights could be drained in an acceptable 20 to 30 minutes. While the program was able to accommodate the varying defueling rates, this should be taken into account when planning future hybrid performance testing. If equipment were available to maintain the battery level to fully charged while running the fuel pump, it would simplify the de-fueling by not having to run the engine.

\section{DISCUSSION}

The results of these tests must be taken as qualitative, not quantitative, for three reasons. The "fleet" consists of only four vehicles and two are of the same make and model. This sample size is certainly insufficient to draw conclusions about HEVs as a class. Secondly, the vehicles tested best represent the initial sales in the US, as such they are indicative but not definitive of the response to fuel for the complete family of HEVs that will soon be available. Finally, as the subjective results indicate, there is significant reason to believe a more complete cold start and driveaway test could be devised to better evaluate hybrid response to fuel. It is possible that these results do not fully capture the fuel response for even this fleet of vehicles. For these reasons, the LS means have been left graphical, and this discussion will speak primarily in terms of significant or non significant response rather than in numerical terms. The primary observations supported by the analytical analysis are: hybrid vehicle/rater combinations can be discriminated with the current test, HEVs do show a response to fuel variables, and the response is trend-wise similar to that of a fleet of current conventional vehicles.

The vehicle LS means analysis and the GLM analysis both show a significant difference between the Civic and the other three vehicles. While the Civic technology is mildly different from that of the other vehicles, it must be remembered that the rater is totally confounded with the vehicle in these analyses, so no meaningful statements can be made about the vehicle alone. Still, it is clear that at least differences in rater-vehicle combinations can be discriminated by the existing cold start test process.

The fuel response across the four vehicles is significant in the GLM and the LS means analysis, indicating that fuels can be discriminated. As might be expected, based on the literature treating fuel interactions with conventional vehicles, the higher DI fuels have higher TWD (99.99\% confidence level) and ethanol degrades performance. In addition, GLM results indicate that the effect of $1 \%$ ethanol relative to one point of DI ( ${ }^{\circ} \mathrm{F}$ scale) is similar to that observed when the main fleet is analyzed in the same fashion (2). While this similarity could not be predicted with certainty a-priori, the fact that HEVs still use a standard internal combustion engine (ICE) makes this result quite reasonable.

The qualitative fuel results are also in accord with past work (10). While the fleet size cannot justify numerical comparison of means and model effects, it is reassuring that the response observed is in general accord with extensive past experience. However, there is significant reason to believe a better cold-start and warm-up driveability test could be created for use specifically with HEVs.

Based on this conclusion the authors and the CRC AVFL committee intend that this piggyback project be followed by a workshop that will focus on the development of a more complete and appropriate HEV cold start driveability test.

The unique operation and performance of HEVs, as discussed above, support the need of such a workshop. There are several HEV issues that should be evaluated during the workshop. They include, but are not limited to, an appraisal of those parts in the existing CRC E-21-94 cycle and warm-up schedule that are inappropriate for HEVs, an appraisal of new or unique aspects of HEV function that interact with fuel, and could require new maneuvers to address, a de-fueling and fueling process for HEVs, a warm-up procedure for HEVs including a standard initial SOC that will contribute to assessment of fuel interactions in HEVs, and a way to obtain that SOC with acceptable reproducibility, a cold-start and driveaway test based on the CRC E-21-94 procedures specifically tailored to effectively determine the cold-start and driveaway driveability of HEVs, and possibly a demerit calculation system modification to calculate TWDs over the HEV cycle.

\section{CONCLUSION}

The findings here, although limited, are important to the future testing and evaluation of HEVs. HEVs showed significant variation among vehicle/rater combinations and among fuels using the existing CRC cold-start and warm-up driveability test, indicating that there is a purpose in testing the driveability of this class of vehicles. Using the existing test, hybrids responded to fuel in a manner similar to the conventional vehicles that were tested. In addition, the HEVs tested had unique driving characteristics that made implementation of the existing CRC cold-start and warm-up driveability test problematic. Therefore, a driveability test specifically tailored to HEV characteristics is recommended in order to properly evaluate this class of vehicles. To accomplish this a new warm-up and refueling process will also be required. 


\section{ACKNOWLEDGMENTS}

The authors and the AVFL Committee wish to acknowledge the dedicated and professional work of the Volatility group of the CRC who conducted the testing and collected the data presented in this report. The authors would also like to thank Harold "Archie" Archibald, Phil Van Acker, Jeff Jetter, and Marie Valentine for their contributions and assitance in developing this report. The AVFL Committee also wishes to thank the Yakama Nation and the owners of the Renegade Raceway for use of the facility.

\section{REFERENCES}

1. SAE 2003-01-0083: "Development of a Power Train for the Hybrid Automobile - The Civic Hybrid"

2. Coordinating Research Council, Inc., 2003 CRC Intermediate-Temperature Volatility Program, CRC Report No. 638, to be published by CRC in late 2003.

3. Kelly, Mihalic, and Zolot, Battery Usage and Thermal Performance of the Toyota Prius and Honda Insight during Chassis Dynamometer Testing, The Seventh Annual Battery Conference on Applications and Advances.

4. Toyota Prius: Best Engineered Car of 2001, Automotive Engineering International, Society of Automotive Engineers, Warrendale, PA.

5. Honda Sales Insight - Insight Facts Book, Honda Motor Company.

6. Honda website; http://www.hondacars.com/models/model_overview. asp

7. SAS windows release 8.02, Users Guide Version 6, 4th edition, Cary NC, 1989.

8. Coordinating Research Council, Inc., CRC Report No. 629, 2001 CRC Hot-Fuel-Handling Program, Appendix C, June 2002.

9. A Report on a Vehicle Fuel Tank Flush Effectiveness Evaluation Program, SwRI Project 08-31088, August 20, 2001, Prepared for CRC in response to CRC Project No. CM-138-01/1.

10. 1995-1997 CRC Study of Fuel Volatility Effects on Cold-Start and Warm-up Driveability with Hydrocarbon, MTBE, and Ethanol Gasoline: Summary Report for Phases 1, 2, and 3, CRC-613, December 1998.

\section{DEFINITIONS, ACRONYMS, ABBREVIATIONS}

AVFL: advanced vehicle fuel and lubricant

Ah: ampere hours

CVT: continuously variable transmission

CRC: Coordinating Research Council
DI: driveability index

ECVT: Electronically controlled continuously variable transmission

F: Fahrenheit

FTP: Federal Test Procedure

HEV: hybrid electric vehicle

ICE: internal combustion engine

kg: kilogram

kW: kilowatt

LS: least squares

NREL: National Renewable Energy Laboratory

NiMH: nickel-metal hydride

SOC: state of charge

TWD: total weighted demerits

V: volts

Wh: watt hours

\section{APPENDIX A}

Discussion of the Merits of Log Transformation:

The log transform used is not uncommon in improving the treatment of datasets where the dependent variable spans two orders of magnitude; it has been used extensively and effectively in past CRC programs. The transform is taken for TWD+1 to avoid an infinite result in cases where there are no demerits observed. A significant byproduct of the transform is that the effects of the variables in a linear analysis (such as GLM) become multiplicative and the coefficients determined become exponents when the reverse transform is taken. That is to say, the resulting model will be of the form $\mathrm{Ln}(\mathrm{TWD}+1)=A v 1+B v 2+C \mathrm{v} 3+\ldots \quad T W D=v 1 A^{*} v 2 B^{*} v 3 C \ldots-1$ where the $A, B$, and $C$ are the coefficients determined in the regression, and the vi are the variable values while the $\mathrm{Vi}$ are the exponential of the variables, e.g. $\mathrm{V} 1=\exp (\mathrm{v} 1)=\exp (\mathrm{DI})$ where $\mathrm{DI}$ is the centered value of driveability index. 